\title{
Modeling phosphorus in the upper Etowah River basin: identifying sources under uncertainty
}

\author{
Z. Lin*, D.E. Radcliffe ${ }^{\star *}$, M.B. Beck ${ }^{\star \star *}$ and L.M. Risse $e^{\star \star * *}$ \\ *BCl Engineers \& Scientists, Inc., Lakel and, FL 33803, USA (E-mail: zlin@sjrwmd.com) \\ **Department of Crop and Soil Sciences, University of Georgia, Athens, GA 30602, USA \\ (E-mail: dradclif@uga.edu) \\ ***Warnell School of Forestry and Natural Resources, University of Georgia, Athens, GA 30602, USA \\ (E-mail: mbbeck@uga.edu)

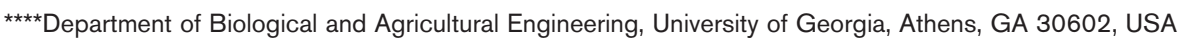 \\ (E-mail: mrisse@engr.uga.edu)
}

Abstract The Uniform Covering by Probabilistic Rejection (UCPR) algorithm was used, in conjunction with the Soil and Water Assessment Tool (SWAT) model, to identify P loads from point source and nonpoint source polluters in the upper Etowah River basin (UERB) in Georgia. The key findings of the research are as follows. The mean absolute error was preferred over the root mean square error as a search criterion for the UCPR algorithm when water quality observations are scarce. The undocumented $P$ load from point sources in the UERB was consistently estimated as about $43 \mathrm{~kg} / \mathrm{d}$ by the proposed method; but the method was not able to identify the broiler litter application rate to the poultry/beef operation pastures. Point sources (both documented and undocumented), poultry/beef operation pastures, and forests are the three major contributors of P. During 1992-1996, on average they accounted for $36.4,31.7$, and $17.2 \%$ of $P$ load from the UERB, respectively.

Keywords Etowah River basin; phosphorus; SWAT; total maximum daily load; uniform covering by probabilistic rejection

\section{Introduction}

Rapid population and economic growth around the Atlanta area in the past decades have imposed increasing threats to the water quality of surrounding water bodies. Lake Allatoona, a reservoir built on the Etowah River, is located about $50 \mathrm{~km}$ northwest of Metropolitan Atlanta. It supplies drinking water for Atlanta suburban counties and receives stormwater and wastewater treatment plant discharges from these areas. A comprehensive study of water quality in Lake Allatoona (the Lake Allatoona Phase I Clean Lakes Diagnostic Feasibility Study, referred to hereafter as the Clean Lakes Study) was conducted under two Clean Lakes Section 319 projects during the 1990's (Rose, 1999). From May 1992 to April 1993, infrequent samples of phosphorus (P) concentrations and stream flow were measured at the points where the 11 main tributaries enter Lake Allatoona. Annual loads were calculated by summing the products of the measured $\mathrm{P}$ concentration, measured flow, and interval between sampling dates. The Clean Lakes Study classified Lake Allatoona as being in transition between mesotrophic and eutrophic, with $\mathrm{P}$ being the primary limiting nutrient for algal growth (Rose, 1999). It was concluded that unless measures were taken to control P inputs to the lake, Lake Allatoona would be unfit for drinking or recreational purposes within ten years. As a result, the Georgia Environmental Protection Division (GAEPD) has imposed a P load restriction of not more than $4.79 \mathrm{mg} / \mathrm{L}$ (1.3 lb/acre-ft) of lake volume per year (GAEPD, 2004) and has listed the entire lake as "not fully supporting the designated uses"(GAEPD, 2006). 
A lake-wide Total Maximum Daily Load (TMDL) for P is scheduled to be developed by 2009 .

The Clean Lakes Study also concluded that, among the 11 main tributaries to Lake Allatoona, the upper Etowah River basin (UERB) contributed about 80 percent of the total $\mathrm{P}$ loading to the lake. The UERB is also a place where more than 50 million chicken broilers are raised in a year (2005 Georgia Farm Gate Value Reports, http://www.agecon.uga.edu/ $\sim$ caed/staffreports.htm, last accessed on 20 June 2007). A typical broiler operation also raises beef cattle on pastures where broiler litter is applied. Pierson et al. (2001) showed that application of broiler litter to grasslands can significantly increase dissolved reactive phosphorus concentrations in surface runoff. However, it is extremely difficult to estimate P loads from the poultry/beef operation pastures, because the areas of pastures receiving broiler litter and the rate of the broiler litter application to the pasture are usually unknown. Moreover, contrary to the common perception that point source pollution is easier to quantify, it is difficult to estimate the $\mathrm{P}$ loads from poultry processing or rendering plants located in the UERB. It was common that these plants were not required by their National Pollutant Discharge Elimination System permits to monitor or remove phosphorus from their effluent. According to the GAEPD Cartersville Regional Office's archives (Buckles, 2005, personal communication), only one poultry processing plant in the UERB has been required to monitor $\mathrm{P}$ concentrations in the plant's discharge and report them in the Discharge Monthly Reports (DMRs) since 2002. Two previous studies (Rose, 1999; Harned et al., 2004) substantially underestimated the percentage of P loads from point sources vs. the total P load from the UERB to Lake Allatoona because of incomplete point source data.

In a TMDL development and implementation program, it is important to be able to differentiate the $\mathrm{P}$ loading sources in the watershed of interest so that the most effective and optimal watershed management strategies can be adopted. Because of such an inherently uncertain situation, it is proposed to use the set-theoretic Uniform Covering by Probabilistic Rejection (UCPR) algorithm, in conjunction with the SWAT model, to systematically estimate the P loads from point source and nonpoint source polluters in the UERB to provide valuable information for the subsequent P load estimation and TMDL development for Lake Allatoona.

\section{Materials and methods}

The upper Etowah River basin model

In this research, the SWAT model (Arnold et al., 1998) was used to simulate P transport in the UERB. From the U.S. Geological Survey (USGS) gauging station at Canton, GA, an area was delineated called the upper Etowah River basin that covered approximately 1619 square kilometres. The watershed was subdivided into 55 sub-basins (Figure 1) and 291 HRUs. The primary land covers were forest $(90.3 \%)$, grassland/pasture $(7.8 \%)$, and urban $(1.6 \%)$; row crop agriculture land use was about $0.3 \%$. The land use data were obtained from the National Land Cover Dataset from 1991 to 1992 and the soils data were obtained from the State Soil Geographic (STATSGO) database. The major soil associations in the UERB are sandy loams, loams, and clayey loams, with Natural Resources Conservation Service hydrologic group categories of B and C, having slow to moderate infiltration rates. Precipitation and temperature data from six National Oceanic and Atmospheric Administration weather stations were obtained to drive the UERB SWAT model. Historic average annual precipitation in the UERB is about $1,500 \mathrm{~mm}$; while the historic average yearly minimum and maximum atmospheric temperatures are around -14.5 and $34.5^{\circ} \mathrm{C}$. Daily stream flow observations were obtained from the USGS gauging station at Canton, GA (No. 02392000). Infrequent total P concentration observations at the same station were measured by the Clean Lakes Study during May 1992-May 1996 (Rose, 1999). The modeling of hydrology and phosphorus for 


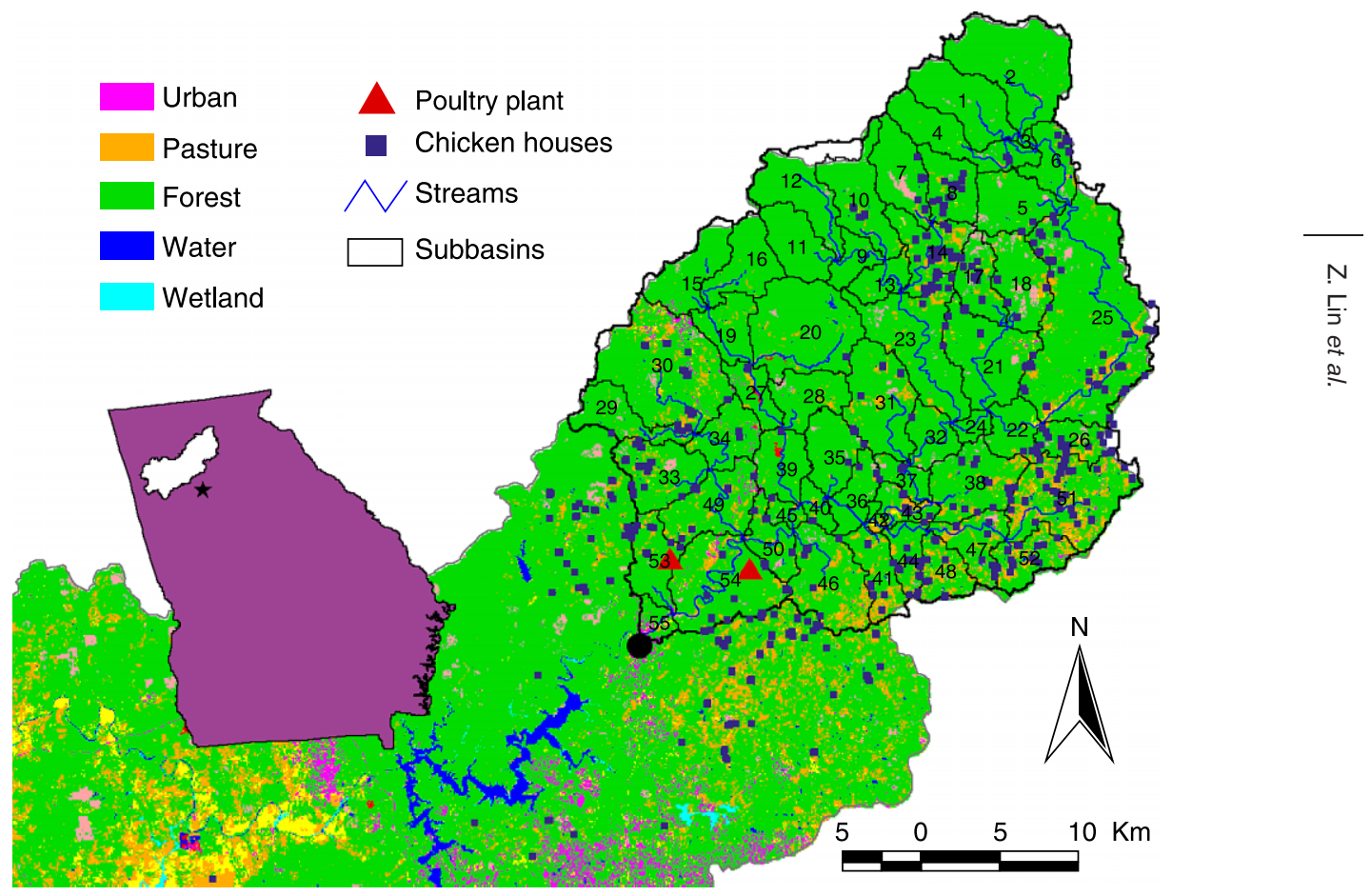

Figure 1 The upper Etowah River basin (solid dot indicates the watershed outlet at Canton, GA)

the UERB was described in Lin and Radcliffe (2006), Radcliffe et al. (2007), and Lin et al. (2007).

\section{Uniform covering by probabilistic rejection algorithm}

The UCPR procedure is a Monte Carlo sampling-based approach to parameter estimation and analysis of uncertainty in environmental and ecological simulation models (Klepper and Hendrix, 1994; Osidele et al., 2006). The objective of UCPR is to search for sub-regions of the parameter domain that contain the best-fitting parameter values, and eventually converge an ensemble of randomly generated parameter vectors onto the global optimum parameter vector. As shown by Steps 3-7 in Table 1, UCPR is computationally efficient, in that it calls the model less frequently than a pure random search. With each subsequent iteration, the value of $r$ changes with the shape and volume of $S$, which either converges on a cluster of optimal parameter sets within $S$, or migrates beyond $S$ to locate other optimal parameter sets in the parameter-sampling domain.

\section{Results and discussion}

\section{Phosphorus-related parameters in SWAT}

The parameters in SWAT that are responsible for P generation, transport, and transformation processes include $\mathrm{P}$ management parameters (such as fertilization rate), soil properties, $\mathrm{P}$ concentrations in soils, erosion and sediment delivery and transport related parameters, as well as parameters governing rainfall-runoff processes in upland areas and channels. However, the parameters governing hydrological processes in the UERB were calibrated with the daily observations of streamflow of the Etowah River at Canton, GA using the method proposed in Lin and Radcliffe (2006) where the associated uncertainty analysis of streamflow prediction was also conducted. In this paper, only those P-related parameters listed in Table 2 are considered, with regard to identifying P sources under uncertainty. 
Table 1 Uniform covering by probabilistic rejection (UCPR) procedure

\begin{tabular}{|c|c|}
\hline Step & Action \\
\hline 0 & $\begin{array}{l}\text { Model parameter vector } \boldsymbol{\alpha}, \boldsymbol{\alpha}^{T}=\left[\alpha_{1}, \alpha_{2}, \ldots, \alpha_{p}\right] \text {, where } p \text { is the dimension of the parameter } \\
\text { vector } \boldsymbol{\alpha} \text {. }\end{array}$ \\
\hline 1 & $\begin{array}{l}\text { Randomly generate } v(v>>p) \text { initial sets of parameter vector, which define a subregion } S \text { in } \\
\text { the entire parameter-sampling domain. }\end{array}$ \\
\hline 2 & Compute the objective function, or mismatch $\left\{\int\right\}$, for each set of the parameter vectors in $S$. \\
\hline 3 & $\begin{array}{l}\text { Calculate the average nearest-neighbor (Euclidian) distance } r \text { between parameter vectors } \\
\boldsymbol{\alpha}^{i}(i=1,2, \ldots, v) \text { in } S \text {. }\end{array}$ \\
\hline 4 & Define subregion $R=c \cdot r$, where $c$ is chosen such that $R$ is only slightly larger than $S$. \\
\hline 5 & Randomly generate a parameter vector, $\boldsymbol{\alpha}^{i+1}$, in subregion $R$. \\
\hline 6 & Calculate the average (Euclidian) distance $r^{i+1}$ between $\boldsymbol{\alpha}^{i+1}$ and $\boldsymbol{\alpha}^{i}(i=1,2, \ldots, v)$ in $S$. \\
\hline 7 & If $r^{i+1}>c \cdot r$, then return to Step 5 ; otherwise continue. \\
\hline 8 & $\begin{array}{l}\text { Substitute the newly generated parameter vector } \boldsymbol{\alpha}^{i+1} \text { into the model and compute the objective } \\
\text { function } J^{i+1} \text {. }\end{array}$ \\
\hline 9 & $\begin{array}{l}\text { If } J^{i+1}<\max \left\{J^{i}\right\}(i=1,2, \ldots, v) \text {, then substitute the parameter vector } \boldsymbol{\alpha}^{i+1} \text { for the vector } \\
\boldsymbol{\alpha}^{i} \text { which generates the worst match; otherwise return to Step } 5 \text {. }\end{array}$ \\
\hline 10 & $\begin{array}{l}\text { If } \max \left\{J^{j}\right\}>\Phi \times \min \left\{J^{j}\right\}(i=1,2, \ldots, v) \text { for } \Phi \in[1.05,1.10] \text {, then return to Step 5; otherwise } \\
\text { search is completed. }\end{array}$ \\
\hline
\end{tabular}

The first three parameters in Table 2 are related to upland erosion processes and the sediment transport process in streams. Erosion in streams or the channel degradation process was not considered because they do not contribute to $\mathrm{P}$ loss from stream bed or banks in the SWAT model. Parameters 4 through 8 are related to soil properties. Their initial values can be estimated based on soil test P and the STATSGO database. Parameters 9 through 13 are related to stream processes. Their values can be estimated using the "uptake length" composite parameter developed by stream ecologists (see also Radcliffe et al., 2007). FRT_KG was defined as the broiler litter application rate to

Table 2 Summary of phosphorus-related parameters in SWAT

\begin{tabular}{|c|c|c|c|c|}
\hline No. & Parameter Name & Definition (Unit) & Fixed Value & Bounds \\
\hline 1 & rSLOPE ${ }^{\dagger}$ & $\begin{array}{l}\text { Change of the average slope steepness of } \\
\text { subbasin }(\mathrm{m} / \mathrm{m})\end{array}$ & 0 & $-0.5-0.5$ \\
\hline 2 & rUSLE_K & $\begin{array}{l}\text { Change of the Universal Soil Loss Equation } \\
\text { (USLE) soil erodibility (K) factor }\end{array}$ & 0 & $-0.5-0.5$ \\
\hline 3 & SPEXP & $\begin{array}{l}\text { Exponent parameter of the power function for } \\
\text { calculating sediment transport in streams }\end{array}$ & 1.5 & $1.0-2.0$ \\
\hline 4 & rSOL_SOLP & $\begin{array}{l}\text { Change of the initial labile P concentration } \\
\text { in surface soil layer }(\mathrm{mg} / \mathrm{L})\end{array}$ & 0 & $-0.5-0.5$ \\
\hline 5 & rSOL_ORGP & $\begin{array}{l}\text { Change of the initial organic P concentration } \\
\text { in surface soil layer }(\mathrm{mg} / \mathrm{L})\end{array}$ & 0 & $-0.5-0.5$ \\
\hline 6 & PHOSKD & Phosphorus soil partitioning coefficient $\left(\mathrm{m}^{3} / \mathrm{Mg}\right)$ & 224 & $50-400$ \\
\hline 7 & PSP & Phosphorus sorption coefficient & 0.29 & $0.01-0.7$ \\
\hline 8 & PPERCO & Phosphorus percolation coefficient $\left(10 \mathrm{~m}^{3} / \mathrm{Mg}\right)$ & 15 & $10-17.5$ \\
\hline 9 & RS2 & $\begin{array}{l}\text { Benthic (sediment) source rate for dissolved } \\
\text { phosphorus in the reach at } 20^{\circ} \mathrm{C} \\
\left(\mathrm{mg} \text { dissolved }-\mathrm{P} / \mathrm{m}^{2} / \mathrm{d} \text { ) }\right.\end{array}$ & 0.001 & $0.001-0.1$ \\
\hline 10 & RS5 & $\begin{array}{l}\text { Organic phosphorus settling rate in the reach } \\
\text { at } 20^{\circ} \mathrm{C}(/ \mathrm{d})\end{array}$ & 0.1 & $0.001-0.1$ \\
\hline 11 & BC4 & $\begin{array}{l}\text { Rate constant for mineralization of organic } P \\
\text { to dissolved } P \text { in the reach at } 20^{\circ} \mathrm{C}(/ \mathrm{d})\end{array}$ & 0.01 & $0.01-0.70$ \\
\hline 12 & MUMAX & Maximum specific algal growth rate at $20^{\circ} \mathrm{C}(/ \mathrm{d})$ & 2.5 & $1.0-3.0$ \\
\hline 13 & $\mathrm{RHOQ}$ & Algal respiration rate at $20^{\circ} \mathrm{C}(/ \mathrm{d})$ & 0.05 & $0.05-0.50$ \\
\hline 14 & FRT_KG & Broiler litter application rate to pastures $(\mathrm{kg} / \mathrm{ha} / \mathrm{yr})$ & - & $100-8,000$ \\
\hline 15 & PCS_KGPD ${ }^{\ddagger}$ & $P$ loads from undocumented point sources $(\mathrm{kg} / \mathrm{d})$ & - & $0-100$ \\
\hline
\end{tabular}

+ The " $r$ " preceding the name of a SWAT parameter represents the relative change of that parameter;

₹ Parameter defined by the authors. 
poultry/beef operation pastures. But it does not necessarily represent the $\mathrm{P}$ source solely from the poultry/beef operations. It also serves as a surrogate of nonpoint sources of $\mathrm{P}$ that were not taken into account by the UERB SWAT model. It may include any nonpoint sources of $\mathrm{P}$ which do not consist of a constant flow of $\mathrm{P}$ load to a receiving water body. PCS_KGPD represents the P load from the undocumented point sources, for which any monitoring data were not available. These sources could include leaking sewer lines or malfunctioning septic systems. The documented point source P loads estimated based on DMRs were already incorporated into the UERB SWAT model as fixed values which were not subject to subsequent uncertainty analysis.

\section{Selecting a search criterion for UCPR}

The usage of the UCPR algorithm for model calibration and uncertainty analysis depends on a suitable criterion, which is a measure of the model's performance in fitting observations, to guide the algorithm in searching for a cluster of optimal parameter sets in the model's parameter domain. A single-valued (weighted) objective function or a binary classification of "acceptable" or "unacceptable" model simulation in comparison with the observed data can be used. In this paper, three types of single-valued objective functions that measure the discrepancy between the SWAT simulated and the observed P concentrations in the Etowah River at Canton, GA were evaluated. They are Root Mean Square Error (RMSE), Mean Absolute Error (MAE), and Matching Ratio (MR). The first two criteria are commonly used in flow and water quality modeling and need no further explanation. The third criterion was designed to treat each observation of $\mathrm{P}$ concentration equally, regardless of its numerical magnitude. The denominator of MR is the total number of $\mathrm{P}$ observations; while the numerator of MR is a summation of a unit function, which takes the value of unity whenever the simulated $\mathrm{P}$ concentration at a given time is close enough to the observed P concentration at the same time (a "match"); otherwise it is zero (no "match"). A "match" is defined as a simulated P concentration at a given time that falls within the error bound of the observed P concentration. Harmel et al. (2006) suggested that the error bound for $\mathrm{P}$ could be as high as $\pm 90 \%$.

In the analysis, except for FRT_KG and PCS_KGPD, all P-related parameters took their fixed values listed in Table 2. Based on the Georgia Farm Gate Value Reports, the total broiler litter produced annually by the poultry/beef operations in the UERB was about 63,000 ton/yr. It was also estimated that there were 8,400 ha of poultry/beef pastures in the UERB. Therefore, the upper limit of the broiler litter application rate (FRT_KG) was selected as $8,000 \mathrm{~kg} / \mathrm{ha} / \mathrm{yr}$. On the other hand, the total P load from the documented point sources was about $55 \mathrm{~kg} / \mathrm{d}$ estimated from the DMRs. But the DMRs for the two poultry processing or rendering plants located in the UERB (see Figure 1) were only available after their wastewater treatment units were upgraded in the early 21st century. It is believed that the P loads from these plants could have been much higher during the 1992 to 1996 modeling period. This may compose the major component of the P load from the undocumented point sources. Hence, $100 \mathrm{~kg} / \mathrm{d}$ was selected as the upper limit for PCS_KGPD.

The results of using the three different criteria to guide the search of the UCPR algorithm are shown in Figure 2. It is not surprising that the RMSE produced a convergence for parameter FRT_KG since it was heavily influenced by the high values of $\mathrm{P}$ concentration recorded under storm flow condition which, in turn, resulted from the nonpoint sources of P loads from the uplands. But RMSE failed to further narrow down the range of PCS_KGPD, the undocumented point sources of P. On the contrary, MR converged on PCS_KGPD, but failed on FRT_KG. This is because the majority of the P concentration measurements were recorded under baseflow condition. Only 10 out of 41 

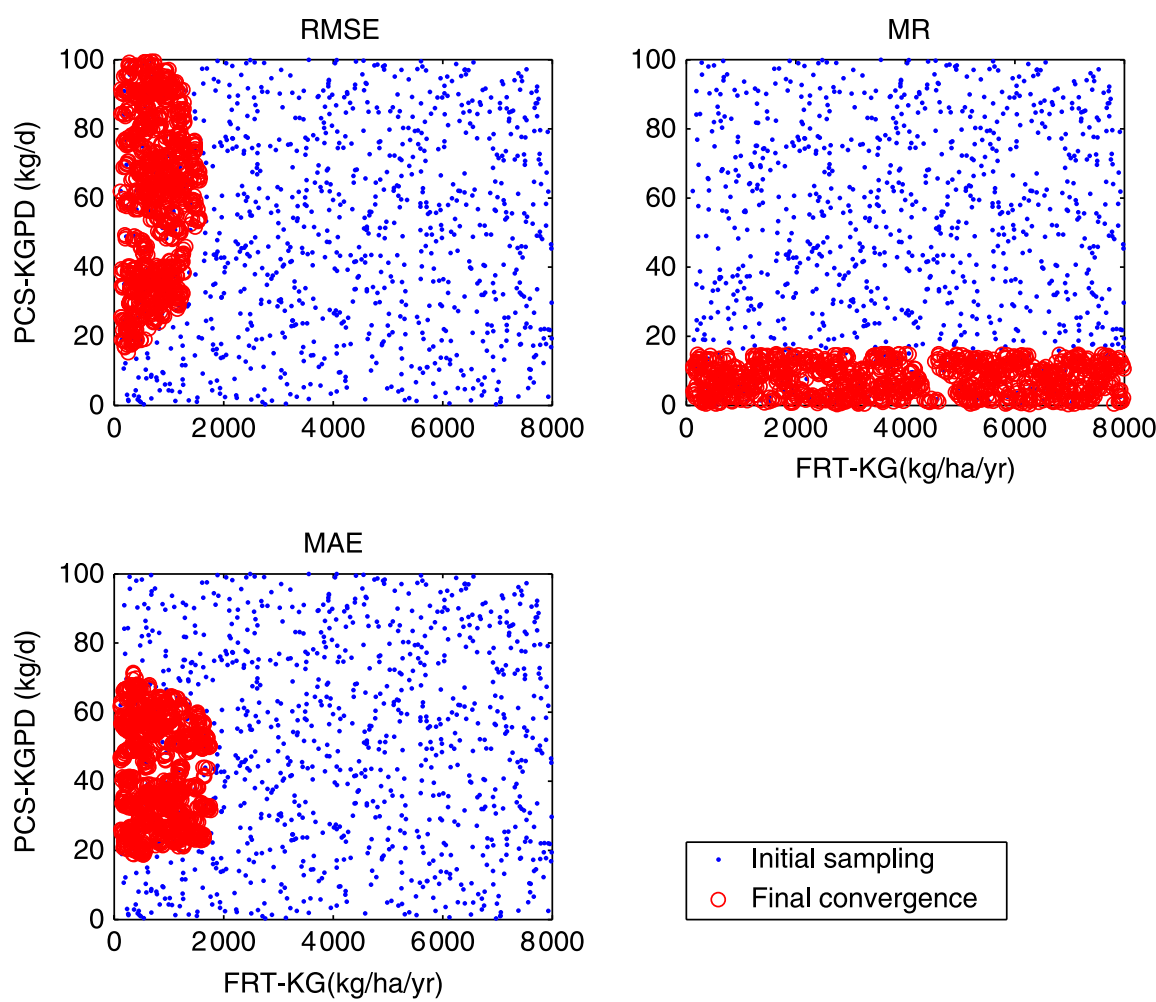

Figure 2 Selection of a search criterion

observations of $\mathrm{P}$ concentration were monitored during storms. Therefore, in principle, MR was designed to treat each observation equally; but, in practice, it favored the baseflow condition because the number of the baseflow observations was much larger than that of the storm flow observations in the context of water quality modeling. It is obvious that this selection process favors the MAE criterion since it converged on both FRT_KG and PCS_KGPD, although it may have underestimated the value of FRT_KG. To the authors' knowledge, most of the broiler litter was applied directly to the pastures near the poultry/beef operations and not exported from the UERB. Therefore, FRT_KG should have taken values in the region closer to its upper limit.

\section{Identifying phosphorus sources accounting for parameter uncertainty}

Instead of fixing all other P-related parameters, all the P-related parameters in Table 2 were estimated along with FRT_KG and PCS_KGPD, using MAE as a search criterion for UCPR. In Figure 3 the histograms of the final convergence of FRT_KG and PCS_KGPD are compared with those in the previous process when the other P-related parameters were fixed. It is not surprising that the estimates of the two parameters had wider histograms when the uncertainties of the other parameters were taken into account. FRT_KG failed to converge on a single cluster, which demonstrated the uncertainty associated with the estimation of the nonpoint source P. However, given knowledge of local practices (there was very little if any export of broiler litter from the watershed in the early 1990s) the third peak $(\sim 7,000 \mathrm{~kg} / \mathrm{ha} / \mathrm{yr})$ provided a realistic estimate for FRT_KG. For PCS_KGPD, although the standard deviation shown in Figure 3d $(22.0 \mathrm{~kg} / \mathrm{d})$ was larger than that shown in Figure $3 \mathrm{~b}(14.2 \mathrm{~kg} / \mathrm{d})$, the two means were comparable ( 42.6 and $42.9 \mathrm{~kg} / \mathrm{d}$, respectively). More interestingly, they are very close to the difference estimated based on the data provided by one of the poultry processing plants before and after its wastewater treatment unit had been upgraded in 2001 . 
(a) 500

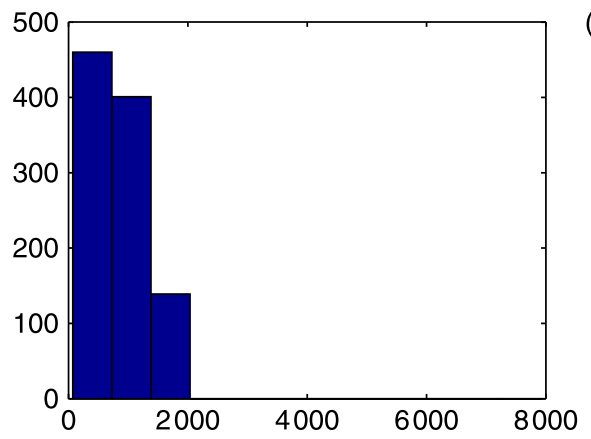

(c)

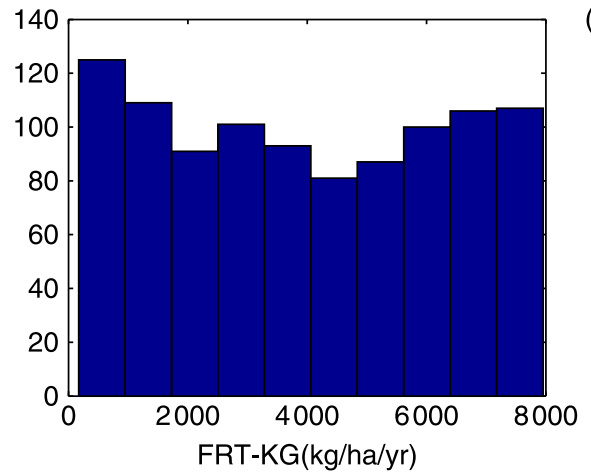

(b)

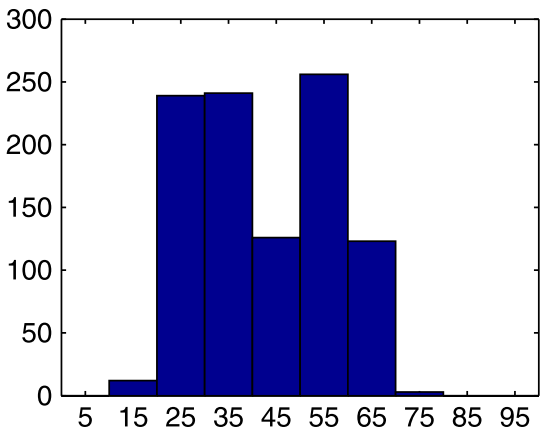

(d)

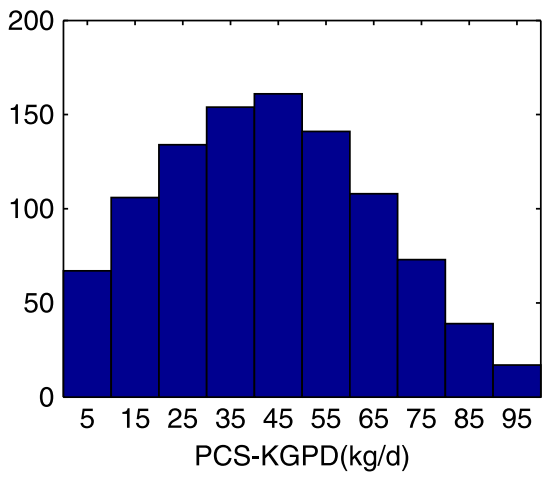

Figure 3 stimation of FRT-KG and PCS-KGPD under uncertainty: (a) and (b) with other P-related parameters fixed; (c) and (d) with other P-related parameters estimated at the same time

The estimate was that the total P load from the two poultry plants in 2000 was $47.2 \mathrm{~kg} / \mathrm{d}$ more than the average in 2002-2003.

Having estimated the P-related parameters under uncertainty, 10 sets of parameters were randomly selected from the final parameter sets (FRT_KG and PCS_KGPD are shown in Figures 3c and Figure 3d, others not shown) to run the UERB SWAT model to estimate the ranges of $\mathrm{P}$ loads from different sources. The results are listed in Table 3. Point source dischargers (documented and undocumented), poultry/beef operation pastures, and forests are the three major contributors. On average, they accounted for $36.4,31.7$, and $17.2 \%$ of the P load from the UERB, respectively, during the modeling period (1992-1996). Urban nonpoint sources and row crops made small contributions to the $\mathrm{P}$ load because of their small percentages of land use in this watershed during the modeling period, although the export coefficients of $\mathrm{P}$ for these two land uses were among the highest (Lin et al., 2007). The urban nonpoint source pollution may have increased considerably in recent years since the urban area in the UERB has more than

Table 3 Annual $P$ loads from different sources in the UERB

\begin{tabular}{lrrrrr}
\hline Sources & \multicolumn{2}{c}{ P Load (kg/yr) } & & \multicolumn{2}{c}{ Percentage (\%) } \\
\cline { 2 - 3 } \cline { 5 - 6 } & Mean & Standard deviation & & Mean & Standard deviation \\
\hline Row crop & 2,850 & 1,924 & & 2.7 & 1.5 \\
Urban & 6,327 & 2,372 & & 6.1 & 1.4 \\
Forest & 18,232 & 10,765 & & 17.2 & 7.9 \\
Pasture receiving broiler litter & 31,873 & 7,525 & & 31.7 & 4.9 \\
Pasture not receiving broiler litter & 6,041 & 2,575 & & 5.9 & 1.9 \\
Point sources & 35,034 & 6,831 & & 36.4 & 11.5 \\
Total P Load & 100,358 & 17,845 & & 100 & 0 \\
\hline
\end{tabular}


tripled from 1992 to 2001. The average annual P load to Lake Allatoona from the UERB was about 100 metric tons. It is smaller than the P load (158 metric tons) estimated by the Clean Lakes Study (Rose, 1999) based on the infrequent samples from May 1992 to April 1993.

\section{Conclusions}

The UCPR algorithm was used, in conjunction with SWAT, to systematically estimate the P loads from point source and nonpoint source polluters in the upper Etowah River basin in Georgia to provide valuable information for subsequent $\mathrm{P}$ load estimation and TMDL development for Lake Allatoona. Given the fact that the water quality observations are scarce (41 measurements of $\mathrm{P}$ concentration in 5 years), especially during storm flows, the key findings of this research were as follows. First, the mean absolute error was preferred over the commonly used root mean square error as a search criterion for UCPR. Second, the undocumented P load from point sources in the UERB was consistently quantified by this method as about $43 \mathrm{~kg} / \mathrm{d}$. However, the method was not able to identify the broiler litter application rate to the pasture, partly because the $\mathrm{P}$ concentration samples are extremely rare under high flow conditions (10 measurements in 5 years). Third, point sources (documented and undocumented), poultry/beef operation pastures, and forests were the three major contributors of P. During 1992-1996, on average they accounted for $36.4,31.7$, and $17.2 \%$ of the P load from the UERB, respectively.

\section{Acknowledgements}

The research was sponsored by a USDA CSREES Water Quality grant \# GEO-200304944 entitled "A Framework for Trading Phosphorus Credits in the Lake Allatoona Watershed". The authors want to thank John Starkey with the U.S. Poultry and Egg Association for his endeavor in mining of point source data in the upper Etowah River basin. Z. Lin is currently contracting with St. Johns River Water Management District, Florida. M. B. Beck is currently Visiting Professor in the Department of Civil and Environmental Engineering at the Imperial College of Science, Technology and Medicine, London.

\section{References}

Arnold, J.G., Srinivasan, R., Muttiah, R.S. and Williams, J.R. (1998). Large area hydrologic modeling and assessment - part 1: model development. Journal of the American Water Resources Association, 34, $73-89$.

GAEPD (2004). Rules and Regulations for Water Quality Control, Chapter 391-3-6, Georgia Environmental Protection Division, Atlanta, GA.

GAEPD (2006). Draft 2006 Lakes/Reservoirs not Fully Supporting Designated Uses, Georgia Environmental Protection Division, Atlanta, GA.

Harmel, R.D., Cooper, R.J., Slade, R.M., Haney, R.L. and Arnold, J.G. (2006). Cumulative uncertainty in measured streamflow and water quality data for small watersheds. Transactions of the ASABE, 49, 689-701.

Harned, D.A., Atkins, J.B. and Harvill, J.S. (2004). Nutrient mass balance and trends, Mobile River Basin, Alabama, Georgia, and Mississippi. Journal of the American Water Resources Association, 40, 765-793.

Klepper, O. and Hendrix, E.M.T. (1994). A method for robust calibration of ecological models under different types of uncertainty. Ecological Modelling, 74, 161-182.

Lin, Z. and Radcliffe, D.E. (2006). Automatic calibration and predictive uncertainty analysis of a semidistributed watershed model. Vadose Zone Journal, 5, 248-260.

Lin, Z., Radcliffe, D.E., Risse, L.M., Romeis, J.J. and Jackson, C.R. (2007). Modeling phosphorus in Lake Allatoona watershed using SWAT: II. effect of landuse change. Journal of Environmental Quality 
Osidele, O.O., Zeng, W. and Beck, M.B. (2006). A random search methodology for examining parametric uncertainty in water quality models. Water Science and Technology, 53(1), 33-40.

Pierson, S.T., Cabrera, M.L., Evanylo, G.K., Kuykendall, H.A., Hoveland, C.S., McCann, M.A. and West, L.T. (2001). Phosphorus and ammonium concentrations in surface runoff from grasslands fertilized with broiler litter. Journal of Environmental Quality, 30, 1784-1789.

Radcliffe, D.E., Lin, Z., Risse, L.M., Romeis, J.J. and Jackson, C.R. (2007). Modeling phosphorus in Lake Allatoona watershed using SWAT: I. developing phosphorus parameter values. Journal of Environmental Quality (submitted).

Rose, P. (1999). Lake Allatoona Phase I Diagnostic-Feasibility Study Report 1992-1997, A.L. Burruss Institute of Public Service, Kennesaw State University, Kennesaw, GA. 